\title{
Exposure to Sexually Explicit Materials and Its Association with Sexual Behaviors of Ambo University Undergraduate Students, 2018
}

\author{
Seifadin Ahmed Shallo ${ }^{1 *}$, Wakeshi Willi Mengesha ${ }^{2}$
}

\footnotetext{
OPEN ACCESS

Citation: Seifadin Ahmed Shallo, Wakeshi Willi Mengesh. Exposure to Sexually Explicit Materials and Its Association with Sexual Behaviors of Ambo University Undergraduate Students, 2018. Ethiop J Health Sci.2018;29(4):461.doi:http://dx.doi.org/ 10.4314/ejhs.v29i4.7

Received: April 14, 2019

Accepted: May 17, 2019

Published: July 1, 2019

Copyright: (C) 2019 Seifadin Ahmed Shallo, et al. This is an open access article distributed under the terms of the Creative Commons Attribution License, which permits unrestricted use, distribution, and reproduction in any medium, provided the original author and source are credited.

Funding: This study was funded by Ambo University research grant project. The funded organization has no role in designing the study, data collection, or manuscript preparation

Competing Interests: The authors declare that this manuscript was approved by all authors in its form and that no competing interest exists.

Affiliation and Correspondence:

${ }^{1}$ Department of Public Health, Ambo

University, Ethiopia

${ }^{2}$ Department of Public Health,

College of Medicine and Health

Sciences, Ambo University, Ethiopia

*Email:

Seifadinahmed8226@gmail.com
}

\section{ABSTRACT}

BACKGROUND: Among the number of reasons that expose the youth to reproductive health risks, lack of adequate information on sexual and reproductive health issues is of prior concern. Given the lack of readily available information about sexual activity to teens, they turn to media for information about sexual norms and may also use the media as a sexual super-peer that encourages them to be sexually active. Therefore, this study was aimed to assess the association between exposure to sexually explicit materials and sexually risky behaviors among undergraduate students of Ambo University, Ethiopia.

METHODS: Institutional based cross-sectional study was conducted among 403 university students in 2018. Study participants were selected by systematic random sampling technique. Self- administered questionnaire was used to collect data. Data were analyzed using SPSS statistical software version 20. Uni-variate, bivariate and multiple logistic regression analyses were done. With 95\% CI, the p-value of less than 0.05 was taken as the level of significance.

RESULTS: About 55\% and 52\% of the university students were exposed to sexually explicit electronic materials throughout their life and in the last 12 months prior to data collection period respectively. Searching for sex information was the top reason for why university students resorted to watching sexually explicit materials. Sexually active students, senior students and male students were more likely to engage in watching sexually explicit electronic materials compared to their counterparts.

CONCLUSION: A high numbers of university students were being exposed to sexually explicit electronic materials for the sake of searching about sexual and related information. This exposure has a significant association with risky sexual behaviors specifically. We highly recommend that university organize awareness creation forum on the area of sexual health, HIV/AIDS and STI, and related matters.

KEYWORD: Sexually explicit materials, risky sexual behaviors, Ambo University 


\section{INTRODUCTION}

Sexually explicit materials refers to textual, visual, or audio materials that typically intends to arouse the viewer and depicts sexual activities and (arouses) genitals in unconcealed ways, usually with close-ups on oral, anal, and vaginal penetration (1). The media has a great role in shaping the sexual behaviors i.e. knowledge, attitudes and sexual practices of adolescents and young people which is as important as family, educational institution and friends can be. For instance, a study conducted in three Asian cities of Shanghai, Hanoi, and Taipe amog more than 17,000 adolescents and young adults indicated that about $45-80 \%$ of adolescents and youths learnt sex information from the media, specifically the internet (2).

The recent advancement of internet-enabled technologies in African countries has significantly changed the way adolescents/young people encounter and consume sexually explicit materials (3). Safer sex is largely absent in sexually explicit materials. As content analysis of such materials had demonstrated, actors used condoms in only $3 \%$ of scenes depicting penile-vaginal intercourse and in only $10 \%$ of scenes depicting penile-anal intercourse (1).

Because they are not well mature psychologically, the younger generation faces challenges in selecting positive messages they may get from such media, and they are easily influenced by them. Longitudinal research findings have demonstrated that sexually explicit material (SEM) exposure affects adolescents' sexual attitudes as well as the initiation of sexual behavior. It has also confirmed that adolescents who visit sexually explicit websites were found to have more permissive attitudes toward sexual activity compared with those who have never been exposed. Similarly, frequent consumer of SE materials had permissive attitude towards extra marital sex $(2,4,5,6)$.

Frequent consumption of pornography is associated with many behaviors and attitudes usually regarded as the characteristics of at risk youth. For instance, a study conducted in USA among school adolescents revealed that frequent exposure to sexual content on television predicts early pregnancy $(5,7)$. A cross-sectional study conducted among high school adolescents in eastern part of Ethiopia also indicated that adolescents who were exposed to SE movies were 2 times more likely to engage in risky sexual behavior compared to those who were never exposed ( 95\% CI: 1.12, 3.44) (8). Frequency of internet use for accessing sexual materials was found to be a predictor of being sexually active and of the likelihood of having multiple sexual partners (9).

The other problems related to exposure to sexually explicit material is its association with many risky sexual behaviors like non-condom use (non-consistent condom use), multiple sexual partner, alcohol use during sexual activity and sexual debut at early age (6).

In developing countries like Ethiopia, youths have been disproportionately affected by reproductive health related problems due to their risky behaviors. These health problems are prominent in areas like universities where a large youth population are found (10).

Among the number of reasons that expose youth to reproductive health risks, lack of adequate information on sexual and reproductive health issues is of prior concern. Given the lack of readily available information about sexual activity to teens, they turn to media for information about sexual norms and may also use the media as a sexual super-peer that encourages them to be sexually active. This lets the media play a significant role in molding youth sexual activity $(2,8)$.

Generally, many studies indicated that sexually explicit material exposure is one of the factors for risky sexual behavior. However, almost all of the studies conducted on this area were from western and other Asian countries, and no studies were conducted on the association between exposure to SE material, and each specific risky sexual behavior. Thus, this study intends to fill this gap.

The other significance of this study was university life is definitely different from preuniversity life for students. In university, the students are out of family control/super vision, and

DOI: http://dx.doi.org/10.4314/ejhs.v29i4.7 
they can be highly influenced by peers. Therefore, this may create conducive environment for them to watch SE materials. Additionally, the availability of free internet (Wi-Fi or cable based) services in university also facilitate consumption of what they desire to access. Thus, the nature of the university students' life mandates to conduct this study. We hope the university youth are the front line beneficiary of this research.

Therefore, the overall objective of this study was to assess exposure to sexually explicit electronic materials and its association with sexual behaviors of Ambo University undergraduate students, 2018.

The following specific questions were addressed:

1. What is the magnitude of exposure to sexually explicit electronic materials among university students?

2. Is there a relationship between exposure to sexually explicit material and sexual risk behaviors of university students?

3. What factors motivate university students to watch sexually explicit electronic materials?

\section{METHODS}

Study area and period: The study was conducted in Ambo University, one of the higher Educational Institutions in Ethiopia. Currently, the university has four campuses with a total of 17,789 regular undergraduate students, out of which 10805 were males and 6984 were females. The Campuses of the university were the Main Campus, the Guder Agricultural Campus, Awaro Institute of Technology Campus and Waliso Campus. Students from the nine regional state of Ethiopia and the 2 cities administrations, i.e. Addis Ababa and Dire dawa join the university each year and live in campus. The programmes given by the university range from three years to five years. The study was conducted from January 1530/2018(11).

Study design: The study design was institutional based cross-sectional.

Study population: The study population was all Ambo University regular undergraduate students who were attending their study programme during data collection period and selected by systematic sampling technique.

Sample size determination: To determine the sample size for this study, outcome variables and various factors significantly associated with the outcome variables were considered. Accordingly, for each specific objective, the sample size was calculated and the larger sample size was used for this study as follows:

The sample size for the first specific objective was calculated with the fallowing factors assumed: level of confidence was $95 \%,\left(Z_{\alpha / 2}\right)=$ 1.96 , marginal error $(d)=0.05$; since we could not obtain a similar study finding on the magnitude of sexually explicit electronic material in Ethiopia, we assumed single population proportion of $(\mathrm{p}=0.05)$ to get the possible maximum sample size. In addition, since the issue under investigation is sensitive, $5 \%$ non-respondense rate was added. By adding the 5\% non-response rate, the total sample size was 403 .

Sampling procedure: In order to obtain representative samples for this study, the sample size was proportionally allocated to each of the four campuses of the university. Then, the samples were collected by applying systematic random sampling using the identity number of the university students which we obtained from the university's registrar office. First, the main campus was selected as the first site of data collection. Then, we divide the total eligible study participants $(17,789)$ by 403 and we got a $\mathrm{K}$ value of 44 . Then, based on the lists of students' identity from main registrar, the other study participants were identified using computer automated methods.

Data collection tools: For data collection, structured questionnaire was prepared based on the reviewed literature and extracting from related studies. The questionnaire was first prepared in English language and then translated into the two common local languages in Ethiopia (Amharaic and Afan Oromo) by two different language experts in the Department of English language and Journalism of Ambo University. Then, the questionnaire was translated back into English by another person of the same department to check its consistent in meaning with first version. The

DOI: http://dx.doi.org/10.4314/ejhs.v29i4.7 
questionnaire contains socio-demographic characteristics of the students, history of exposure to sexually explicit materials, sexual behaviors of the students and other related backgrounds.

Data collection procedure: First, the study participants were oriented about the objectives of the study, their rights, benefits and risks of participating in the study. After that, selfadministered technique was used using structured questionnaire containing both open-ended and close-ended questions translated into local languages (Amharic and Afan Oromo) for eligible participants. For data collection, data collectors' (first degree holders in statistics) were recruited and trained by the principal investigator. A oneday training was given to them by the principal investigator on the objective of the study, consent taking and data handling methods for data collectors. During field work, Supervision was carried out by the principal and the co-researchers.

Study variables: The outcome variable for this study was exposure to sexually explicit electronic materials. Socio-economic and demographic characteristics such as sex, age, duration of stay in the university, ethnic group, religious group, parents' educational status, income of parents, open discussion on sexual issues with a family member were the independent variables.

\section{Operational definitions}

Sexual behaviors- refer to the number of sexual partners, condom use during sexual intercourse, type of sexual intercourse, history of sex with commercial sex workers or a person whom one does not know.

Sexually explicit electronic materials- refer to any video type electronic materials that typically intend to arouse the viewer and depict sexual activities and (arouses) genitals in unconcealed ways, usually with close-ups on oral, anal, and vaginal penetration; could be online or offline accessible types (12).

Exposure to sexually explicit material- relates exposure to at least one of the SE electronic materials visually (by watching) (13).

Risky sexual behaviors- refer to a person who had history of one of the following: history of multiple sexual partners, non-condom use during sexual intercourse, having anal/and oral sex, history of sex with commercial sex workers or a person whom one does not know, alcohol use during sexual intercourse.

Data quality: To ensure the data quality of our study, the following measures were taken. The questionnaire was developed by reviewing relevant literatures on the subject, pre-tested and modified where necessary. Training was also given to data collectors and supervisors. Besides, orientation was given to the study participants on the objective of the study. During field work, each completed questionnaire was checked immediately after it was received from respondents to ascertain that all the questions had been answered consistently.

Data management and analysis: After the collected data was checked for completeness, it was entered into Epi Data Version 3.02 for documentation and cleared for error. After checking for consistency of the entered data, data was exported to SPSS Version 20 statistical software for analysis.

Descriptive statistics: Frequency distribution, median/mean were computed. In order to assess the association between dependent and independent variables, first bi-variate analysis was done. Variables which had association with the dependent variable at $p$-value $<0.25$ during bivariate analysis were included in logistic regression analysis. In addition, variables which were highly associated with the dependent variable from previous studies were also considered to be candidate for multivariable logistic regression. Odd ratio with $95 \% \mathrm{CI}$, and level of significance at $\mathrm{p}<0.05$ were considered for statistical significance.

Ethical consideration: Ethical clearance was obtained from the Ethical Review Committee of the College of Medicine and Health Sciences, Ambo University. During the field work, the objective of the study was clearly explained for the study participants, confidentiality of the data to be collected and the right not to participate were also assured. Before starting the data collection process, written consent was taken from each

DOI: http://dx.doi.org/10.4314/ejhs.v29i4.7 
respondent after they read and signed the consent form.

\section{RESULTS}

Socio-demographic and substance use characteristics' of the respondents: Out of the 403 study participants intended to be included in this study, 376 completed the questionnaire, making the respondent rate of $93.3 \%$. The mean age (the data is normally distributed) of the participants was $21.42 \pm(1.94 \mathrm{SD})$. The majority of the participants were males $(68.6 \%)$, and in the age of 21-25 (Table 1).

Concerning substance use among, about $28 \%$, $16 \%$ and $7 \%$ of the respondents had behaviors of drinking alcohol, chewing khat and smoking cigarettes respectively. These behaviors indicate both their past and/or their present status (Table 2).

Table 1: The socio demographic distribution of Ambo University Undergraduate students, 2018

\begin{tabular}{|c|c|c|}
\hline VARIABLES & FREQUENCY & PERCENT (\%) \\
\hline \multicolumn{3}{|l|}{ Age } \\
\hline $15-20$ & 151 & 40.2 \\
\hline 21-25 & 213 & 56.6 \\
\hline $26-30$ & 12 & 3.2 \\
\hline \multicolumn{3}{|l|}{ Sex } \\
\hline Male & 258 & 68.6 \\
\hline Female & 118 & 31.4 \\
\hline \multicolumn{3}{|l|}{ Marital Status } \\
\hline Never Married & 229 & 60.9 \\
\hline In Formal Marriage & 44 & 11.7 \\
\hline Boy-Girl Friends & 96 & 25.5 \\
\hline Divorced & 7 & 1.9 \\
\hline \multicolumn{3}{|l|}{ Student's Batch } \\
\hline $1 \mathrm{st}$ & 132 & 35.1 \\
\hline 2nd & 126 & 33.5 \\
\hline 3rd & 111 & 29.5 \\
\hline 4th & 7 & 1.9 \\
\hline \multicolumn{3}{|l|}{ Fathers Educational Status } \\
\hline Unable to read and write & 141 & 37.5 \\
\hline Primary Education & 85 & 22.6 \\
\hline Secondary Education & 30 & 8.0 \\
\hline Diploma And Above & 120 & 31.9 \\
\hline \multicolumn{3}{|l|}{ Mothers Education } \\
\hline Unable to read and write & 180 & 47.9 \\
\hline Primary Education & 103 & 27.4 \\
\hline High School & 37 & 9.8 \\
\hline Diploma And Above & 56 & 14.9 \\
\hline \multicolumn{3}{|l|}{ Fathers Occupation } \\
\hline Farmer & 232 & 61.7 \\
\hline Civil Servant & 106 & 28.2 \\
\hline Daily Laborer & 10 & 2.7 \\
\hline $\begin{array}{c}\text { Others(Pensioner, Not Alive, } \\
\text { Religious Father) }\end{array}$ & 28 & 7.4 \\
\hline
\end{tabular}

DOI: http://dx.doi.org/10.4314/ejhs.v29i4.7 
Table 2: substance abuse of Undergraduate Students, Ambo University,2018

\begin{tabular}{ccc}
\hline Variables & Frequency & Percent (\%) \\
\hline Alcohol Use & 269 & 71.5 \\
never & 56 & 14.9 \\
yes, but not now & 51 & 13.6 \\
yes currently & 350 & \\
Smoking cigarette & 14 & 93.1 \\
never & 12 & 3.7 \\
yes, currently & & 3.2 \\
yes, but not currently & 314 & \\
Chat Chewing & 62 & 83.5 \\
never & 137 & 16.5 \\
Yes, currently & 55 & 36.4 \\
How spending leisure & 167 & 14.6 \\
watching films & 9 & 44.4 \\
Walking to cafe & & 2.4 \\
reading books/religious & & \\
two of the above &
\end{tabular}

Exposure to Sexually explicit Electronic materials and Sexual Behaviors of the participants: About $82 \%$ of the participants responded that they knew the existence of sexually explicit materials such as video, written or audio forms. Internet, i.e. facebook, Youtube and Google were mentioned as the main accessible source of SE materials by about $45 \%$ of the study participants. The participants were asked whether they watched sexually explicit videos throughout their life time and in the last 12 months. Although to different extents, about 207(55.1\%) reported that they were exposed to sexually explicit videos at least once and, out of this, 108(52\%) responded that they watched sexually explicit videos in the last 12 months prior to data collection period. Internet based source $(45.4 \%)$ was the commonest source of SE materials. The majority of the respondents watched SE electronic materials with their friends. Out of SE video exposed individuals, 142(68.6\%) watched by intentionally searching of videos. The participants were asked what motivates them to watch SE materials, and $37.7 \%$ of those exposed claimed that they watched for searching sexual information. The participants were asked about their sexual experience. Out of the total participants, $143(38 \%)$ were sexually active with the mean age at first sexual coitus being 18.6( $\mathrm{SD} \pm 2.97)$. Of those who were ever sexually active, $93.01 \%$ engaged in vaginal sex, and $6.99 \%$ experienced mixed sex (vaginal and anal or Oral). Concerning the type of explicit sex exposure, nearly $60 \%$ were exposed to video portraying vaginal sex followed by a mix of vaginal and oral sex or vaginal and anal sex which accounts for about $29 \%$.

DOI: http://dx.doi.org/10.4314/ejhs.v29i4.7 
Table 3: Sexually explicit electronic material exposure status among Ambo University Undergraduate students, 2018

\begin{tabular}{lrr}
\hline Variables & Frequency & Percent \\
\hline Do you know the existence SE materials & & \\
Yes & 308 & 81.9 \\
No & 68 & 18.1 \\
From where did you hear & 92 & 24.5 \\
Friends & 169 & 44.9 \\
internet & 37 & 9.8 \\
TV or radio & & \\
Have you ever watched SE videos & 207 & 55.1 \\
Yes & 169 & 44.9 \\
No & & \\
With whom did you watch SE videos & 74 & 35.7 \\
alone & 121 & 58.5 \\
With Friends & 11 & 5.3 \\
Both of the above & & \\
From where did you access SE videos & 18 & 8.7 \\
Television & 24 & 11.6 \\
renting videos & 93 & 44.9 \\
Internet based social media & & \\
(fb, whatsapp) & 66 & 31.9 \\
you tube & 4 & 1.9 \\
\hline from my friends PC or Mobile & & \\
\hline
\end{tabular}

Table 4: Multivariable Logistic Regressions analysis on association between SE electronic materials exposure and Sexual behaviors, and Factors associated with it among Ambo University Undergraduate students, 2018.

\begin{tabular}{|c|c|c|c|c|c|}
\hline \multirow[t]{2}{*}{ Covariates } & \multicolumn{2}{|c|}{ SEM exposure status } & \multirow{2}{*}{$\begin{array}{l}\text { COR with } 95 \% \\
\text { CI }\end{array}$} & \multirow{2}{*}{$\begin{array}{l}\text { AOR with 95\% } \\
\text { CI }\end{array}$} & \multirow{2}{*}{$\begin{array}{l}\text { P- } \\
\text { values }\end{array}$} \\
\hline & $\begin{array}{c}\text { EVER } \\
\text { exposed }\end{array}$ & $\begin{array}{l}\text { NEVER } \\
\text { Exposed }\end{array}$ & & & \\
\hline \multicolumn{6}{|l|}{ Age } \\
\hline $15-19$ & 21 & 24 & $0.38(0.162,0.904)$ & $0.12(0.01,1.3)$ & 0.08 \\
\hline $20-24$ & 154 & 131 & $.51(0.263,1.01)$ & $1.04(0.28,3.84)$ & 0.96 \\
\hline$>=25$ & 32 & 14 & 1 & & \\
\hline \multicolumn{6}{|l|}{ Sex } \\
\hline male & 160 & 98 & $2.466(1.56,3.85)$ & $2.2(1.28,3.77)$ & 0.005 \\
\hline female & 47 & 71 & 1 & & \\
\hline \multicolumn{6}{|l|}{ Relationship } \\
\hline never in any relationship & 112 & 117 & $0.52(0.34,0.80)$ & $0.91(.29,2.86)$ & 0.87 \\
\hline In Relationship & 95 & 52 & 1 & & \\
\hline \multicolumn{6}{|l|}{ Batch of the student } \\
\hline $1^{\text {st }}$ year & 65 & 67 & $0.44(0.26,0.74)$ & $0.67(0.37,1.23)$ & 0.60 \\
\hline $2^{\text {nd }}$ year & 61 & 65 & $0.43(0.25,0.72)$ & $0.43(.24,0.79)$ & 0.006 \\
\hline $3^{\text {rd }}$ year and above & 81 & 37 & 1 & & \\
\hline \multicolumn{6}{|l|}{ Drunk alcohol } \\
\hline Never Drunk & 117 & 152 & $0.145(0.082,0.258)$ & $0.17(0.09,0.31)$ & $<.001$ \\
\hline Ever drunk & 90 & 17 & 1 & & \\
\hline \multicolumn{6}{|l|}{ Sexually active status } \\
\hline Yes & 104 & 39 & $3.37(2.15,5.28)$ & $1.95(1.15,3.32)$ & 0.014 \\
\hline No & 103 & 130 & 1 & & \\
\hline
\end{tabular}

DOI: http://dx.doi.org/10.4314/ejhs.v29i4.7 


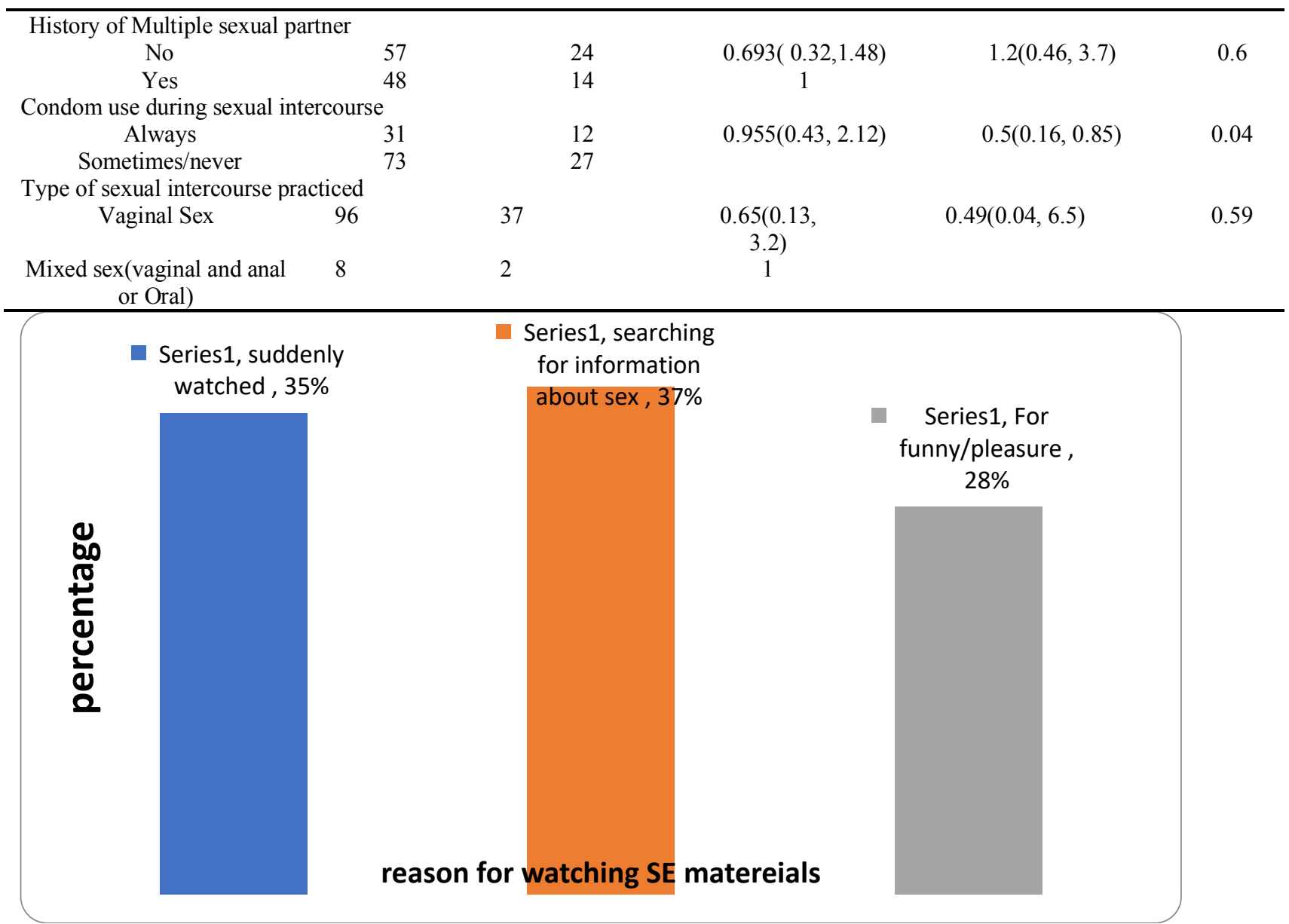

Figure 1: Reasons for watching sexually explicit Electronic materials among Ambo University Undergraduate students, 2018

\section{DISCUSSION}

This is the first study conducted to assess sexually explicit electronic material exposure and sexual behavior of university students in Ethiopia. Our result suggested that about $55 \%$ of university students were exposed to SE electronic materials at least once in their life, and out of this, about $52 \%$ were exposed in the last 12 months prior to data collection period. This finding is lower compared to a study conducted in Hawassa, Southern Nations and Nationalities, Ethiopia, and many other studies in western countries $(12,14,15)$. The difference could be due to differences in study subjects, places, and measurements (i.e. some study measures only internet based exposure; some others measure electronic, textual and audio materials). For instance, the study in Hawassa was conducted among preparatory students, urban residents, where accessibility for electronic material was high.
Additionally, in contrast to ours, they also measured all types of sexually explicit materials i.e. video, textual and audio materials. In the case of the university, students come from a mix of urban and rural parts of the country. However, our measurement focused only on electronic based SE materials. This could be the reason for the discrepancy of the results. On the other hand, the finding our study is greater compared to a study done in Southwest Nigeria, among in-school students $(37 \%)$. The difference could be due to the fact that the Nigerian study measured only exposure over 3 months prior to data collection while the current study measured the life time and in the last tweleve month exposure status . cultural differences, differences in intern accessibility can be also the reason for the varaiation of the finding (16).

Out of SE electronic material exposed university students, about $37.7 \%$ claimed that searching for sexual information was their top reason. This is a significant

DOI: http://dx.doi.org/10.4314/ejhs.v29i4.7 
number and supports the published study conducted among preparatory students in Hawassa, SNNP of Ethiopia (14).

The information which is portrayed on the sexually explicit electronic materials may forward some positive information for observers. However, due to the fact that the majority of the University students are not well matured enough psychologically and physically too, they are easily influenced and face challenges in selecting only the positive information. Due to this, information from SE materials is potentially harmful. Our finding from logistic regression analysis indicated that exposure to SE electronic material is associated with non-condom use and alcohol use during sexual intercourse. As logistic regression revealed, those who watched SE electronic material were 2 times more likely not to use (non-consistently use) condom during sex. Alcohol consumption is a known risky sexual behavior which puts the students at risk for acquiring STI, HIV/AIDS and/or unwanted pregnancy along with its consequences. Alcohol use during sex increases the probability of irresponsible sex specifically not using condom $(4,17)$.

The factors associated with SE electronic material exposure were assessed using multiple logistic regressions by controlling for confounders. Accordingly, sexually active students were nearly 2 times more likely to be exposed to $\mathrm{SE}$ electronic materials [95\% CI: $\mathrm{AOR}=1.95(1.15,3.32)]$. A finding from Nigeria also indicated that frequent exposure to SE material predicts sexual activity and multiple sexual partners, which supports our finding. This is for the fact that the majority of university students lack sufficient awareness about sex and sexual life. For this reason, when they become sexually active, they start to search for information about sex. The other finding of this study, i.e. about $37.7 \%$ of SE electronic material exposed university students claimed that they watched for searching about sex information could also substantiate this finding $(13,18,8)$.

Overall, males were more likely to be exposed to SE electronic materials compared to female $[95 \% \mathrm{CI}$ : $\mathrm{AOR}=2.2(1.28,3.77)]$. This is similar with the finding from Hawassa, Ethiopia, and the study in Italy among grade 12 and vocational students $(2,14,19)$. Even though we could not get scientifically proved reason for the difference in exposure status between males and females, we believe that the difference is due to sociocultural influences. In Ethiopia, it is a taboo for a female to clearly engage in such behaviors, and even if they engage they are less likely to report it as they know it is taboo.

The limitation of this study is that we did not included qualitative data which may complement the quantitative finding. In addition, since this study is cross-sectional, the association does not mean causative.

In conclusion, in this study, we tried to assess the magnitude of SE electronic materials exposure and its association with sexual risk behaviors among university students. Our finding revealed that:

$>$ a high numbers of university students were exposed to SE electronic materials;

$>$ the main reason for the exposure was searching information about sex and related issue;

$>$ internet based social media were the commonest source SE electronic materials;

$>$ there is a significant association between exposure to SE electronic materials and risky sexual behaviors;

$>$ exposure to SE electronic materials was higher among males, sexually active students, and senior students compared to their counterparts.

Ambo University should work on filling gaps related to sexual and reproductive health related information. To do this, we highly recommend that there should be continuous awareness creation for students on the area of sexual health, safe sex, STI and HIV related issue. Such intervention should give priority to sexually active students. University students should get guidance on the potential harmful effects of sexually explicit material, and on how to capture only positive information if done so.

In addition, the university's administration should focus on extra-curriculum activities like sport and different clubs (e.g. HIV/AIDS and others) so that students will spend their leisure times there. This will have two advantages: the students will acquire some knowledge about their health and they will substitute the time to watch sexually explicit material as part of their recreation during leisure times. Finally, we suggests that the ICT Directorate should lay restriction on pornographic videos which are accessible on internet.

\section{ACKNOWLEDGMENTS}

We would like to acknowledge Ambo University for funding this study. We would also like to thank our study participants, and our data collectors for their collaboration.

\section{REFERENCES}

1. Jochen Peter, Patti M. Valkenburg. The Use of Sexually Explicit Internet Material and Its

DOI: http://dx.doi.org/10.4314/ejhs.v29i4.7 
Antecedents: A Longitudinal Comparison of Adolescents and Adults J. ournal Heal Commun. 2011;40:1015-1025.

2. Lou C, Cheng Y, Gao E, Zuo X, Emerson MR. Media's Contribution to Sexual Knowledge, Attitudes, and Behaviors for Adolescents and Young Adults in Three Asian Cities. J Adolesc Heal 19 2019];50(3):S26-36.: https://www.sciencedirect.com/science/article/p ii/S1054139X11006677?dgcid=raven_sd_reco mmender email

3. Chandra $\bar{A}$, S. C. Martino. Does watching sex on television predict teen pregnancy? Findings from a national longitudinal survey of youth. Pediatrics,. 2008;122:1047-1054.

4. Braun-Courville DK, M. Rojas. Exposure to Sexually Explicit Web Sites and Adolescent Sexual Attitudes and Behaviors . J Adolesc Heal. 2009;45:156-62.

5. Paul JW, A. Analisa. "Internet Pornography and U.S. Women's Sexual Behavior: Results From a National Sample. Mass Commun Soc. 2013;16(5):617-38.

6. Hald GM, Kuyper L, Adam PCG, de Wit JBF. Does Viewing Explain Doing? Assessing the Association Between Sexually Explicit Materials Use and Sexual Behaviors in a Large Sample of Dutch Adolescents and Young Adults. J Sex Med 2019];10(12):2986-95. https://www.sciencedirect.com/science/article/p ii/S1743609515302253?dgcid=raven_sd_recom mender email

7. Carl Göran S., Ingrid Å., et.al. Frequent users of pornography. A population based epidemiological study of Swedish male adolescents . J Adolesc. 2011;34:779-788.

8. Hirbo Shore, Addisu Shunu. Risky sexual behavior and associated factors among youth in Haramaya Secondary and Preparatory School, East Ethio. J Public Heal Epidemiol, 2015;9.

9. SAsekun -Olarinmoye, E. Asekun-Olarinmoye, al. et. Effect of mass media and Internet on sexual behavior of undergraduates in Osogbo metropolis, Southwestern Nigeria. . Adolesc Health Med Ther, 2014;5:15-23.

10. Tesfaye S., Abulie T. Sexual and Reproductive Health Problems and Service Needs of
University Students in South East Ethiopia: Exploratory Qualitative Study . Sci J Public Heal. 2013;1(4):184-8.

11. Ambo university registrar Office. No Title. 2018.

12. Jochen Peter, P. M. Valkenburg. Adolescents' Exposure to Sexually Explicit Material on the Internet . SAG journals, 2006;33(2):178-204.

13. Lioul B, Jemal H. Does exposure to sexually explicit films predict sexual activity of the inschool youth? Evidence from Addis Ababa high schools." Ethiop $J$ Heal Dev, 2009;23(2):183-9.

14. Habesha T, Aderaw Z, Lakew S. Assessment of exposure to sexually explicit materials and factors associated with exposure among preparatory school youths in Hawassa City, Southern Ethiopia: a cross-sectional institution based survey. Reprod Health 16 2019];12(1):86. http://reproductive-health

16. Adeolu J, Owoaje E, Olumide A. Association between exposure to sexually explicit content in the electronic media and sexual intentions of in-school adolescents in Southwest Nigeria. Int J Adolesc Med Health,30(3). http://www.degruyter.com/view/j/ijamh.2018.3 0.issue-3/ijamh-2016-0056/ijamh-20160056.xml

17. Amon E, Angelina M. Multiple sexual partners and condom use among 10 - 19 year-olds in four districts in Tanzania: What do we learn? . BMC Public Health. 2011;11:490.

18. Tesfaye S., AbulieT., al. et. Risks for STIs/HIV infection among Madawalabu University students, Southeast Ethiopia: a cross sectional study. Biomed Cent Reprod Heal. 2013;10:38.

19. Romito P, Beltramini L. Watching Pornography. Violence Against Women. 2019];17(10):1313-26.

http://journals.sagepub.com/doi/10.1177/10778 01211424555

DOI: http://dx.doi.org/10.4314/ejhs.v29i4.7 